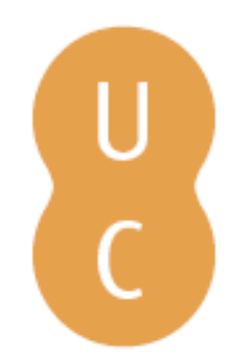

\title{
nommalina
}

\section{Fundamentos teóricos da Medicina Dentária para aplicação forense}

Autor(es): $\quad$ Corte-Real, Ana; Oliveira, Carina

Publicado por: Imprensa da Universidade de Coimbra

URL

persistente: URI:http://hdl.handle.net/10316.2/38400

DOI: $\quad$ DOI:http://dx.doi.org/10.14195/978-989-26-0963-8_1

Accessed : $\quad$ 26-Apr-2023 11:54:37

A navegação consulta e descarregamento dos títulos inseridos nas Bibliotecas Digitais UC Digitalis, UC Pombalina e UC Impactum, pressupõem a aceitação plena e sem reservas dos Termos e Condições de Uso destas Bibliotecas Digitais, disponíveis em https://digitalis.uc.pt/pt-pt/termos.

Conforme exposto nos referidos Termos e Condições de Uso, o descarregamento de títulos de acesso restrito requer uma licença válida de autorização devendo o utilizador aceder ao(s) documento(s) a partir de um endereço de IP da instituição detentora da supramencionada licença.

Ao utilizador é apenas permitido o descarregamento para uso pessoal, pelo que o emprego do(s) título(s) descarregado(s) para outro fim, designadamente comercial, carece de autorização do respetivo autor ou editor da obra.

Na medida em que todas as obras da UC Digitalis se encontram protegidas pelo Código do Direito de Autor e Direitos Conexos e demais legislação aplicável, toda a cópia, parcial ou total, deste documento, nos casos em que é legalmente admitida, deverá conter ou fazer-se acompanhar por este aviso. 


\section{IDENTIFICAÇÃO EM MEDICINA DENTÁRIA FORENSE}

ANA CORTE-REAL DUARTE NUNO VIEIRA COORDENAÇÃO 
Capítulo I

Fundamentos teóricos da Medicina Dentária para aplicação forense

Análise da Face

Anatomia Dentária

Odontometrias

Odontograma

Análise Oclusal 


\section{RESUMO:}

O método científico utilizado para identificação baseia-se em cinco pressupostos, designadamente, singularidade, imutabilidade, perenidade, reprodutibilidade e classificação de uma característica. Neste capítulo são destacadas as características de análise da face, dos dentes e respetivas interrelações. A Medicina Dentária revela-se importante no âmbito da identificação forense, na medida em que: os dentes são altamente resistentes a agentes agressivos; a morfologia de cada peça dentária é peculiar; o registo radiográfico de uma ficha clínica é executado por rotina no tratamento dentário em individuos vivos; a metodologia de análise é tecnicamente fácil e de baixo custo; e por último, o registo radiográfico das arcadas dentárias de cadáveres pode constar de uma base de dados. Na identificação, a taxa de sucesso através das estruturas dentárias pressupõe a determinação de características genéricas, tais como o género, a idade e a afinidade populacional do indivíduo, complementadas com os exames morfológicos e de análise genética que possuem elevado poder discriminatório. A documentação de fatores individualizantes, como por exemplo, características orofaciais, odontometrias, morfologia dentária e oclusão, adquire um elevado valor pericial quando aplicado um método comparativo com registos clínicos anteriores. A identificação positiva é atribuída quando um conjunto de características coincidentes permite estabelecer, sem qualquer discrepância, a identidade do indivíduo. Uma das dificuldades da identificação por análise dentária é a insuficiente informação dos achados anatómicos num contexto epidemiológico, ou seja, a exígua distribuição das frequências das distintas características morfológicas por afinidade populacional, que permita atribuir um valor de probabilidade de identificação positiva. Face ao exposto, a fiabilidade do resultado de uma identificação por análise dentária está em relação com o universo de suspeitos.

\section{PALAVRAS-CHAVE:}

identificação positiva, unicidade, imutabilidade, perenidade, reprodutibilidade, classificação.

\section{ABSTRACT:}

The scientific method used for identification is based on five assumptions: uniqueness, immutability, perpetuity, reproducibility and classification of a feature. This chapter highlights the characteristics of face analysis, teeth analysis and their interrelationships. Dentistry proved to be important in the context of forensic identification since: teeth are highly resistant to aggressive agents; the morphology of each tooth is distinctive; the radiographic registration of a medical record is routinely performed in the dental treatment in living individuals; the method of analysis is technically simple and inexpensive, and finally, the radiographic registration of the dental arches of cadavers can be contained in a database. In identification, the success rate through the dental structures presupposes the establishment of generic features such as gender, age and population affinity of the individual, supplemented with morphologic tests and genetic analysis that have high discrimination power. Documenting individualizing factors such as orofacial characteristics, teeth metric analysis, tooth morphology and occlusion, acquires a high expert value when applied to a comparative method with previous clinical records. Positive identification is assigned when a matching set of features allows you to establish without any discrepancy, the identity of the individual. One of the difficulties of dental identification is insufficient information of the anatomical findings in an epidemiological context, that is, the negligible distribution frequency of the different morphological characteristics by population affinity, that allows to assign a probability value of positive identification. Considering the above, the consistency of a result of identification by dental examination is in relation to the universe of suspects.

\section{KEYWORDS:}

positive identification, uniqueness, immutability, perpetuity, reproducibility, classification. 


\section{1. INTRODUÇÃO}

Os avanços na tecnologia, indústria e ciência têm vindo a proporcionar uma melhoria da qualidade de vida e a promover uma maior misceração entre os povos. Novas causas e formas de morte têm surgido no mundo moderno. As mortes não naturais ocorrem com assinalável frequência e cada vez mais os indivíduos morrem fora do seu país de origem. O mundo atual continua a assistir a múltiplas situações de criminalidade, de violação dos direitos humanos, de conflitos bélicos e de catástrofes, com um crescente número de pessoas desaparecidas. A identificação de indivíduos vivos ou cadáveres constitui atualmente uma área particularmente relevante no âmbito das Ciências Forenses. O direito individual à identificação é atualmente um dos direitos universais de maior relevância.

A obtenção de uma identificação positiva é o resultado que melhor contenta as situações de entes desaparecidos, a resolução de investigações criminais e a elaboração da decisão jurídico-legal. O método de identificação deve obedecer a um procedimento científico, pelo que, apesar da sua semelhança e de servirem um propósito comum, é conveniente que se faça a distinção entre reconhecimento e identificação. O reconhecimento entende-se como a identificação de algo ou de alguém que já se conhece previamente; é um procedimento empírico, subjetivo e sem rigor científico, como por exemplo, o reconhecimento de uma prótese dentária ou de uma assinatura pelo notário. A identificação médico-legal é definida por um conjunto de características que distinguem um indivíduo dos restantes, no enquadramento biológico, social, cultural, religioso, jurídico-legal e económico. Por outro lado, a identificação é executada por técnicos especializados e é caracterizada pelo uso de técnicas científicas e meios propícios de modo a obter um resultado. O reconhecimento pode ser utilizado como método secundário e complementar do processo de identificação [1].

O método científico utilizado no processo de identificação é baseado em cinco pressupostos: singularidade, imutabilidade, perenidade, reprodutibilidade e classificação de uma característica. Podemos subdividir este método em cinco unidades de estudo: visual, datiloscópica, antropológica, genética e dentária.

A identificação visual de um indivíduo compreende a caracterização sequencial, exaustiva e estandardizada da "aparência» do mesmo. $\mathrm{O}$ aspeto visual compreende a análise da face, no plano frontal e/ou de perfil, o estudo da sua forma, contorno, proporcionalidade e simetria que resultam das relações estáticas e dinâmicas dos seus componentes ou unidades visuais [1,2]. As alterações visuais podem estar relacionadas com as circunstâncias da morte ou com artefactos iatrogénicos, post mortem ou devido a processos patológicos, como é o caso, de problemas dermatológicos. Os artefactos iatrogénicos referem-se essencialmente às manobras de reanimação ou procedimentos cirúrgicos e diagnósticos, enquanto as alterações post mortem podem ser resultantes de fenómenos de decomposição cadavérica, ação não intencional de terceiros (ex.animais) ou de fatores ambientais (calor/frio, meio líquido). Quanto maior for o intervalo post mortem maior será a probabilidade de existir artefactos passíveis de modificar fatores de identificação. Nestes casos, poder-se-á considerar insuficientes os dados 
para a atribuição de uma identificação positiva. A complementariedade das unidades de estudo é o procedimento ideal.

Neste capítulo, destaca-se o andar inferior da face definido pela relação entre os dentes de ambas as arcadas dentárias. Nesta interação considera-se as características dentárias como o número de peças dentárias, o seu relativo posicionamento e detalhes anatómicos, com particular destaque para os dentes anteriores, incisivos e caninos [3]. Os dentes são elementos individualizantes, caracterizados pela sua elevada resistência a agentes lesivos externos. Adiante, será efetuada uma descrição sequencial e estandardizada da morfologia (macroscópica e radiológica) dos dentes ou suas estruturas similares (ex.próteses dentárias). O canino é o dente que apresenta um relevante contributo na caracterização individual. A simetria harmoniosa da face relaciona-se com a existência e o posicionamento dos incisivos centrais superiores, que definem igualmente a forma e o posicionamento dos lábios [4]. As características morfológicas das peças dentárias e as suas interrelações contribuem para a singularidade da dentadura humana.

Nos capítulos seguintes serão abordadas as restantes unidades de estudo integradas no método de identificação e outros temas de relevância médico-legal.

\section{2 ANÁLISE DA FACE}

A face pode ser caracterizada numa vista frontal ou de perfil, pela sua forma e proporcionalidade e, ainda, pela sua simetria $[1,4]$. Estes parâmetros são avaliados numa posição reproduzível pelo profissional de saúde; consideram-se duas as posições intermaxilares de referência (ou seja, de oclusão) para a análise da face: a posição de intercuspidação máxima habitual (PIM) e a posição de relação cêntrica $(\mathrm{RC})$. A primeira obtida com o indivíduo sentado, em que a posição de ambas arcadas dentárias corresponde à posição de boca fechada de modo a permitir a deglutição. A segunda, corresponde à posição de contacto das duas arcadas dentárias, em que o côndilo mandibular tem a posição mais recuada na respetiva articulação temporomandibular. Considera-se que não havendo uma posição ideal de oclusão, a posição de PIM pode ser empregue na análise da face, uma vez que corresponde a uma posição de fácil reprodução e mais fidedigna entre os registos do mesmo indivíduo $[5,6]$.

Deste modo ao analisar a face considera-se uma componente óssea e uma componente dentária, caracterizada pelo número, anatomia e interrelações dentárias.

Numa vista frontal, a proporção entre a altura e a largura, define uma face curta ou longa, variando consoante o género e apresentando a proporção de 1.3:1 nas mulheres e de 1.35:1 nos homens [4]. A altura é avaliada sobre a linha média facial ou plano sagital mediano, que deverá englobar a linha média dentária superior, definida pela linha de união dos incisivos centrais superiores. A relação entre a distância intergoníaca e a zigomática define uma face larga ou estreita, podendo ainda ser classificada em redonda, oval ou quadrada (figs. I.1).

No que se refere aos planos horizontais podemos considerar a linha do plano oclusal, definida pelos caninos superiores e inferiores, bem como outras linhas de referência, designadamente 

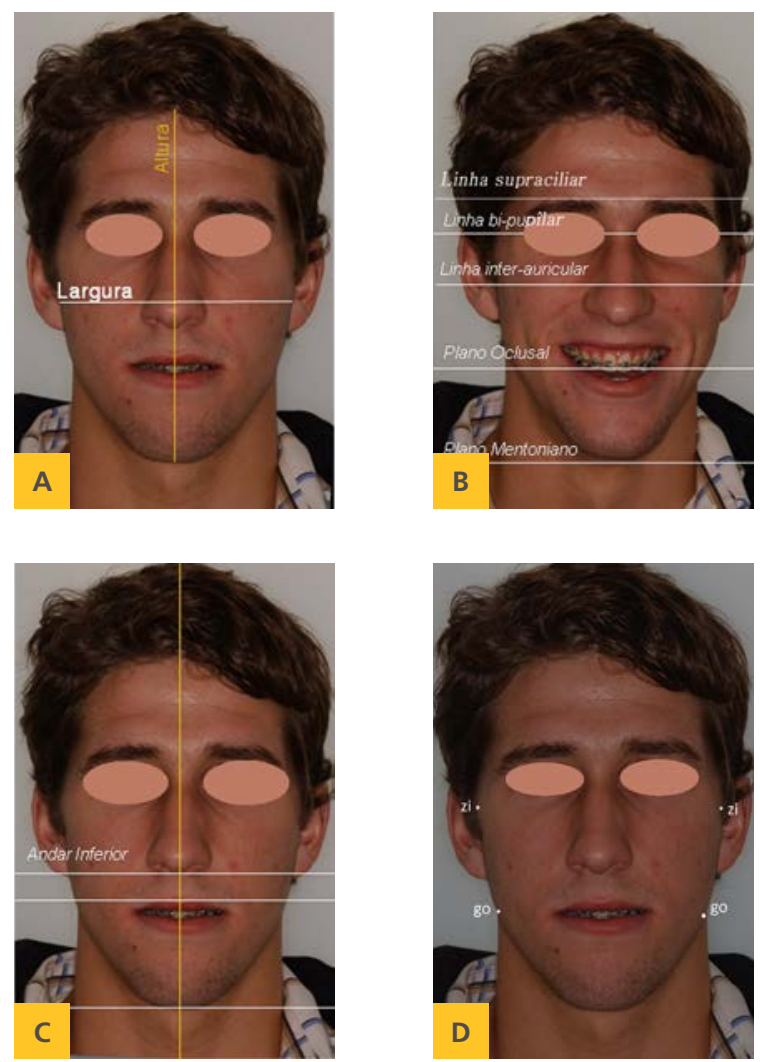

Figuras I.1 (A,B, C e D) - Registo fotográfico na análise frontal da face. (A) Face oval e longa. (B) Face simétrica caracterizada pelo paralelismo dos planos horizontais com a linha de referência bi-pupilar. (C) Desequilíbrio do andar inferior da face caracterizado pelas alturas, lábio superior e lábio inferior/mento. (D) Referência aos pontos goníaco (go) e zigomático(z) bilateralmente. Cortesia da FMUC 2013.

a linha bi-pupilar, o plano inter-auricular e o plano mentoniano (fig. I.1B).

A proporcionalidade vertical é definida pelos três andares da face, superior (tríquio-glabela), médio (glabela-subnasal) e inferior (subnasal-mento cutâneo), que para harmonia facial, devem possuir idênticas proporções (fig. I.1C).

Numa vista de perfil, a face é analisada pelo posicionamento sagital dos tecidos moles nos andares médio e inferior (figs. I.2) e para um equilíbrio harmonioso, estes dois andares deverão
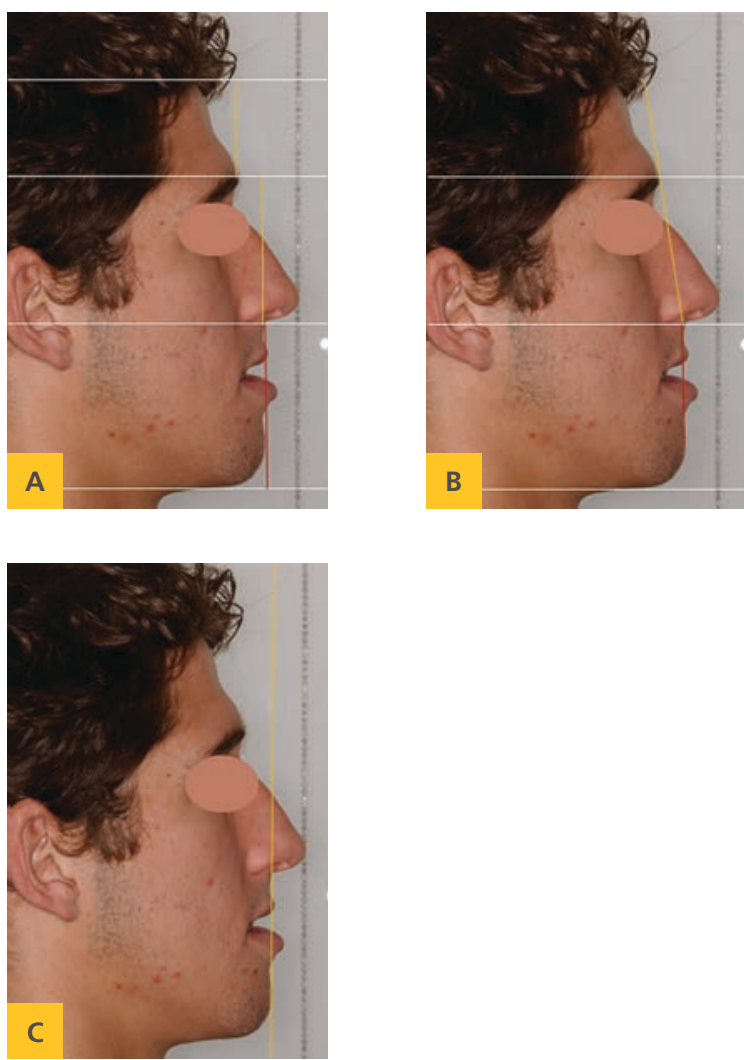

Figuras I.2 (A,B e C) - Registo fotográfico na análise antero-posterior da face. (A) Linhas de referência. (B) Avaliação do ângulo facial correspondente ao tipo de Classe III. (C) Avaliação da posição antero-posterior dos lábios e mento em relação à linha vertical subnasal, normoposição do lábio superior e protrusão labial inferior. Cortesia da FMUC 2013.

estar posicionados anteriormente ao andar superior (fig. I.2A).

O sorriso relaciona-se com a dinâmica labial e com a disposição dentária e gengival (localização da gengiva em relação à coroa do dente). A análise do sorriso tem importância crescente na nossa sociedade sendo um elemento chave no diagnóstico ortodôntico, na reabilitação protética dentária e na avaliação do dano corporal, uma vez que realça o impacto estético (figs. I.1, I.2). A observação dos lábios, numa vista frontal, 


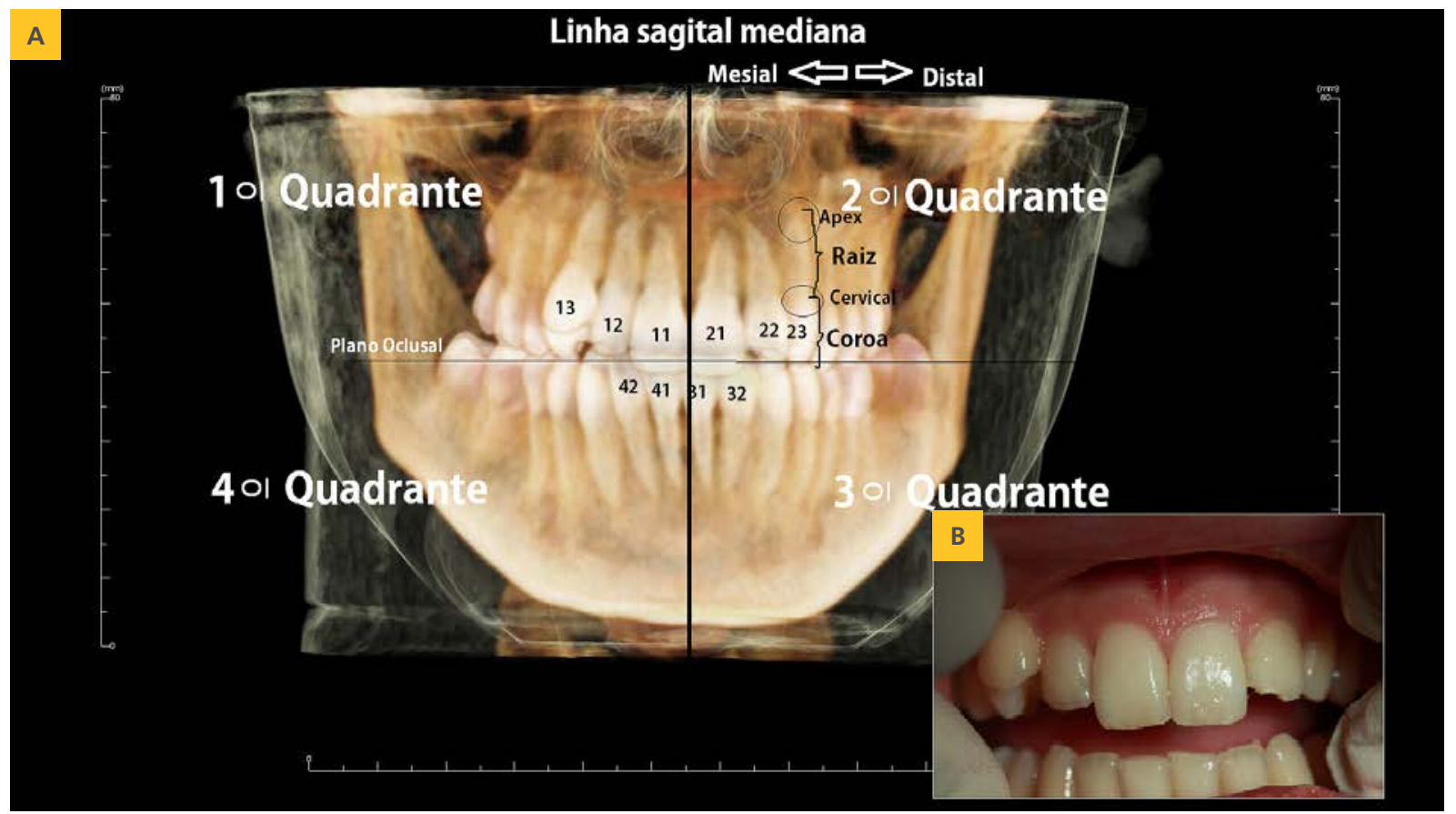

Figuras I.3 (A e B) - Nomenclatura. (A) Reconstrução tridimensional por imagens DICOM, destaque na orientação dos quatro quadrantes pelas linhas, sagital mediana e do plano oclusal; designação dos dentes anteriores superiores e incisivos inferiores segundo a nomenclatura da Federação Dentária Internacional (FDI). (B) Fotografia frontal correspondente a imagem em A.

é efetuada na posição de repouso e de perfil. A exposição dos incisivos, associada a um valor superior de trespasse (distância compreendida entre os bordos dos incisivos centrais, superior e inferior) horizontal e vertical traduz a incompetência labial, ou seja, os lábios não entram em contacto; nesta situação, a relação dos dentes anteriores e do respetivo suporte esquelético (componente ósseo maxilar superior e inferior) definem um sorriso. Do ponto de vista dentário, o posicionamento dos lábios é dependente da posição dento-esquelética e do grau de inclinação ântero-posterior dos dentes anteriores da arcada superior.

\section{I.3. ANATOMIA DENTÁRIA}

A aplicabilidade da unidade de estudo dentária na identificação, pressupõe o conhecimento da histologia dentária e morfologia dos elementos básicos do sistema estomatognático, os dentes. Os dentes, como elementos da cavidade oral, per si, 32 definitivos e 20 decíduos, podem ser caracterizados face à sua morfologia e odontometrias (mensurações). Por outro lado, podemos caracterizar a disposição dos dentes em grupo, nas arcadas dentárias e as suas interrelações. A análise destes distintos elementos está na base da singularidade da dentadura humana que 

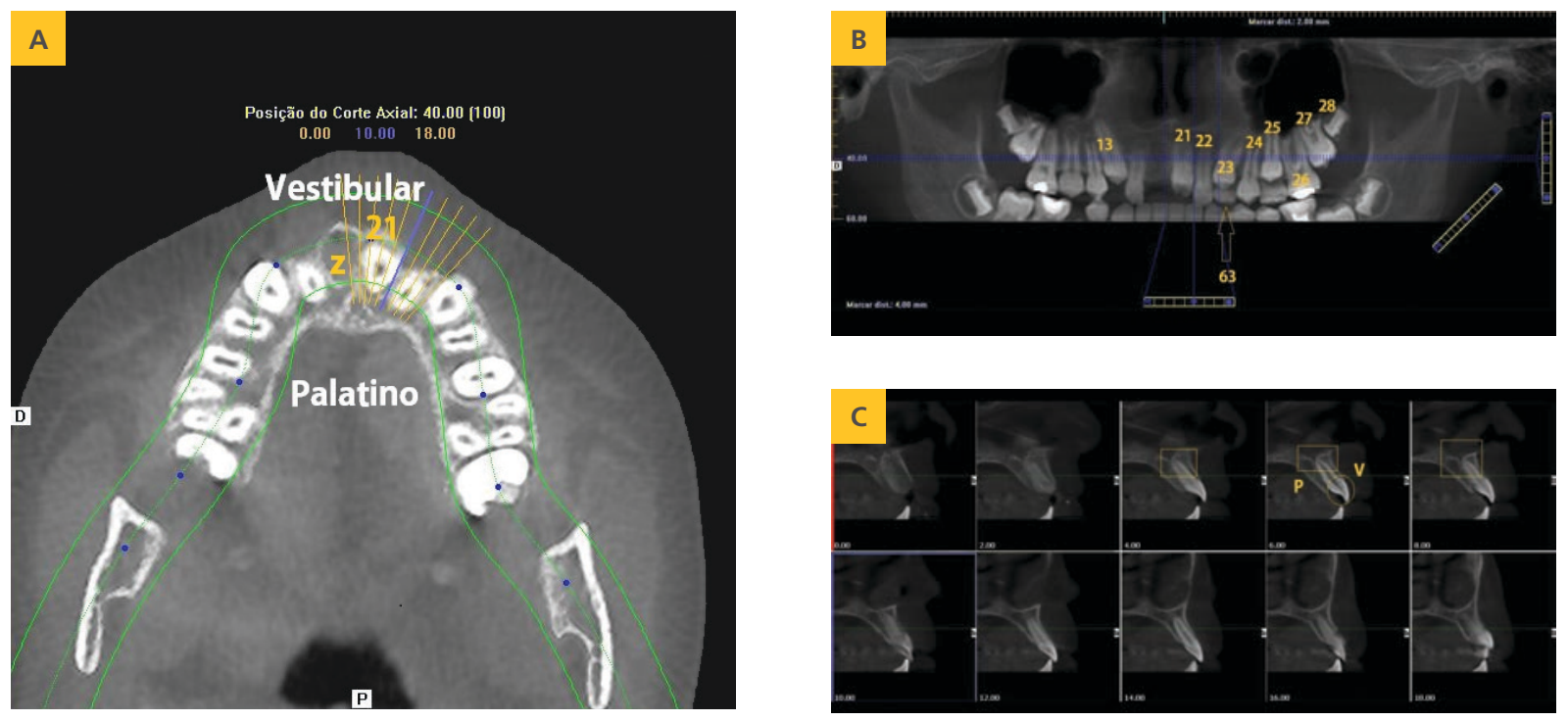

Figuras I.4 (A,B e C) - Cortes tomográficos por técnica de feixe cónico, de uma criança de 12 anos de idade que sofreu traumatismo oro-facial. (A) Corte axial horizontal (segundo linha assinalada em B), destaque para o alvéolo vazio (z) na posição correspondente ao dente 11. (B) Apresentação em panorâmica, destaque para o dente decíduo canino superior esquerdo (63), posição intrusiva do 21 e radiopacidades das restaurações dos primeiros molares definitivos. (C) Cortes axiais sagitais, na análise do estado de apicificação do 21 (destaque retangular) e respetiva orientação espacial do contorno vestibular (V) e do contorno palatino (P).

corresponde a um dos pressupostos do método de identificação.

Neste sentido, a utilização de uma terminologia universal permite um registo percetível por qualquer profissional de saúde, em relação ao qual seguiremos neste livro as normas de nomenclatura da Federação Dentária Internacional (FDI) (figs. I.3 e I.4).

\section{I.3.1 ODONTOMETRIAS}

A identificação pelo estudo dentário baseia-se em métodos biométricos e aplica-se no âmbito da investigação forense. As odontometrias correspondem às mensurações realizadas entre detalhes anatómicos dentários, podendo ser individuais (num único dente) ou em grupo.

\section{- Odontometrias individuais}

As odontometrias individuais relevantes no âmbito médico-legal podem dividir-se em três categorias: na primeira as mensurações mésio-distais (coronária e cervical); na segunda as mensurações vestíbulo-palatino/lingual (palatino relacionado com a arcada superior e lingual com a arcada inferior) (coronária e cervical); e por último, as mensurações longitudinais (a 


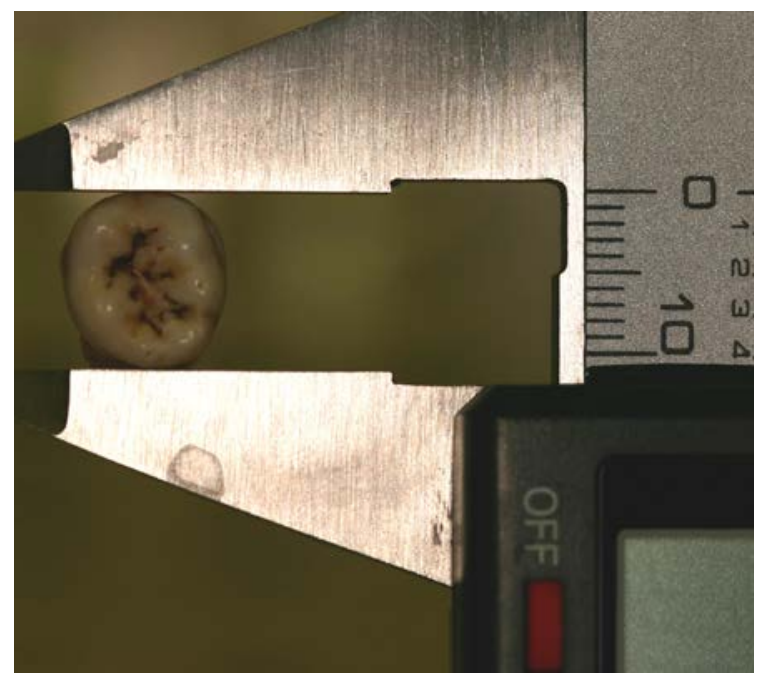

Figura I.5 - Fotografia da mensuração, manual e digital, da largura mesio-distal coronária (11 mm). Técnica visualizada pela face oclusal do primeiro molar inferior direito.

altura coronária anatómica e o comprimento radicular).

As mensurações mésio-distais podem ser medidas com uma craveira digital e correspondem ao maior diâmetro do dente a nível coronário, que do ponto de vista prático corresponde à maior dimensão mesio-distal da área obtida num registo de mordida (figs. I.5, I.6 e I.7).

Esta mensuração por sofrer alterações fisiológicas ou iatrogénicas por spliting (desgaste efetuado por disco em instrumento rotatório, por exemplo, durante uma reabilitação ortodôntica para realinhamento do dente na arcada dentária), opta-se pela sua determinação,

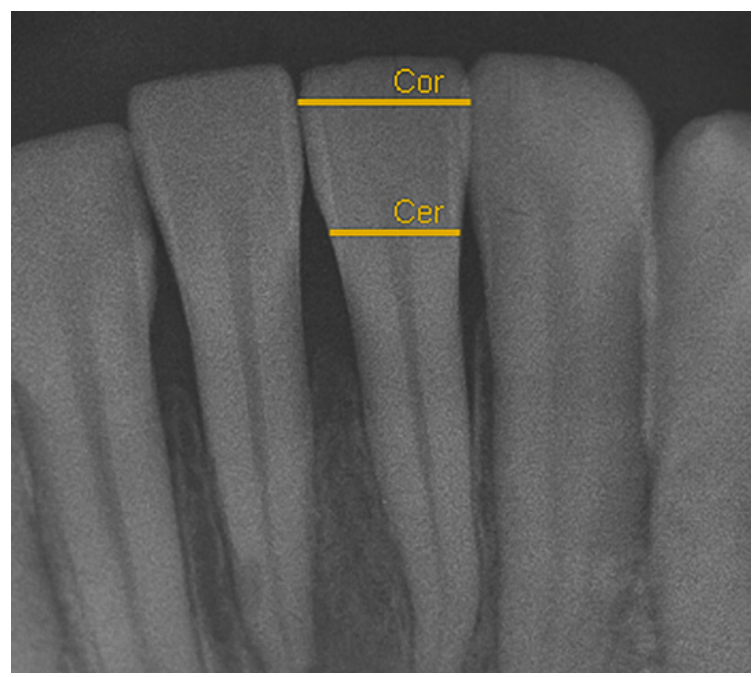

Figura I.6 - Imagem obtida por radiografia periapical, destaque para a técnica de mensuração das larguras mesio-distais, coronária (Cor) e cervical (Cer), no incisivo central inferior esquerdo.

com maior exatidão, a nível cervical, na linha coronária do equador do dente ou no detalhe anatómico em que termina o cemento e inicia o esmalte, designada por junção amelo-cementária (JAC) entre o plano mesial e o distal (fig. I.6). Esta mensuração tem a sua aplicabilidade como parâmetro de avaliação numa estimativa da idade biológica e num processo de identificação por comparação de registos clínicos ante e post mortem.

As mensurações vestíbulo-palatinas (nos dentes da arcada superior) e vestíbulo-linguais (nos dentes da arcada inferior) podem ser igualmente medidas com craveira digital, tendo 


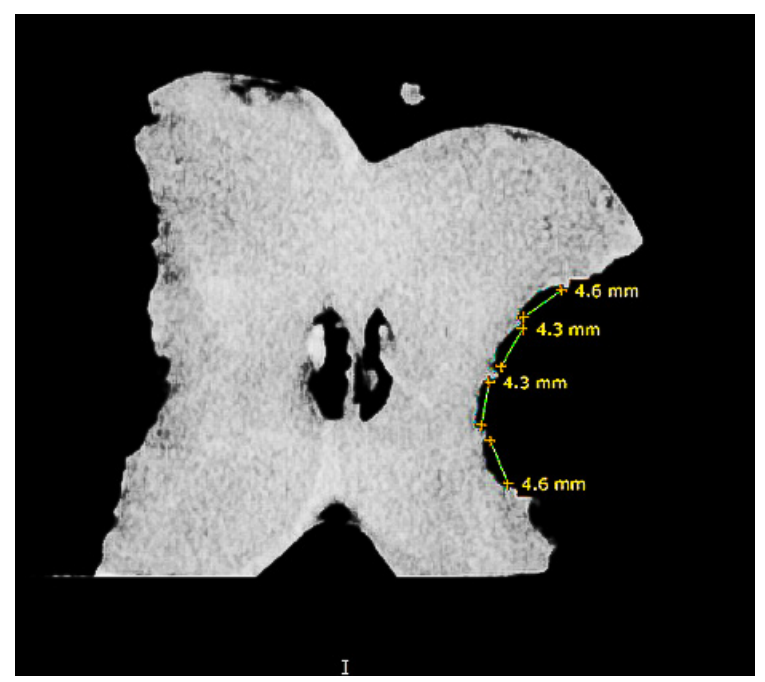

Figura I.7 - Imagem obtida de corte axial coronal por tomografia axial de feixe cónico de uma maçã mordida. Técnica de mensuração das larguras mesio-distais coronárias de cada incisivo inferior envolvido no registo das marcas dentárias, por software In Vivo ${ }^{\circ}$ Anatomage ${ }^{\mathrm{TM}}$.

aplicação prática no estudo da estimativa da idade e do género [7]. À semelhança da odontometria mesio-distal, podem ser efetuadas na linha coronária do equador do dente a nível da JAC (junção amelo-cementária).

A nível da coroa pode ser determinada a altura coronária anatómica, mensuração que corresponde à maior dimensão vertical da coroa, obtida do ponto mais oclusal da cúspide (no canino, prémolar e molar) ou bordo livre (nos incisivos) ao ponto de maior convexidade coronária, na face vestibular do dente. Esta determinação poderá sofrer alterações fisiológicas ou iatrogénicas (ex. reabilitações com material

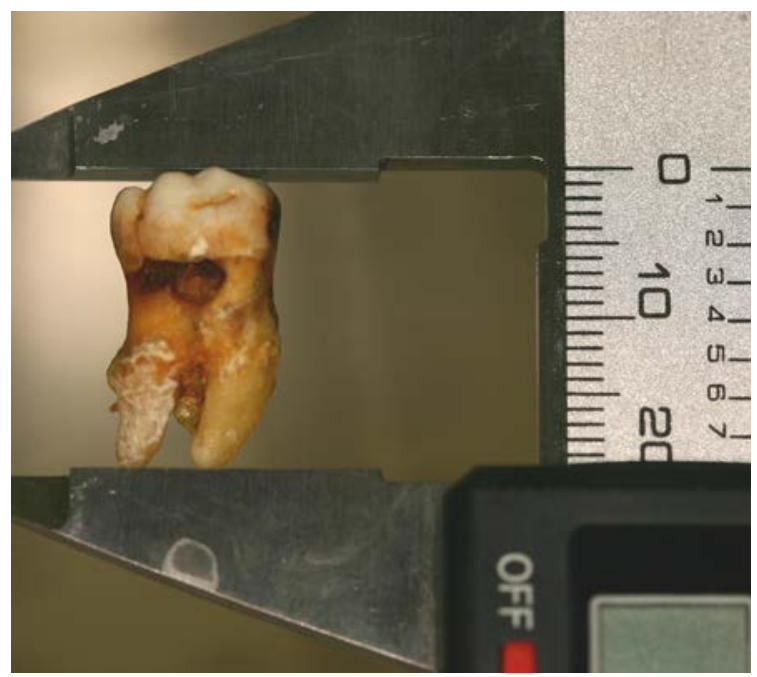

Figura 1.8 - Fotografia da mensuração, manual e digital, da altura total do dente $(20 \mathrm{~mm})$. Técnica visualizada pela face vestibular do primeiro molar inferior direito.

restaurador). Alternativamente pode ser efetuada a mensuração da altura coronária na cavidade oral, designada por altura da coroa clínica, que corresponde à dimensão certical da coroa do ponto mais oclusal ao ponto de maior concavidade da linha gengival.

A nível radicular podemos efetuar mensurações em dentes fora do osso alveolar (fig. I.8) e em películas radiográficas (fig. I.9). As odontometrias do comprimento radicular e altura total do dente destacam a sua aplicação prática nos métodos de estimativa da idade biológica. 


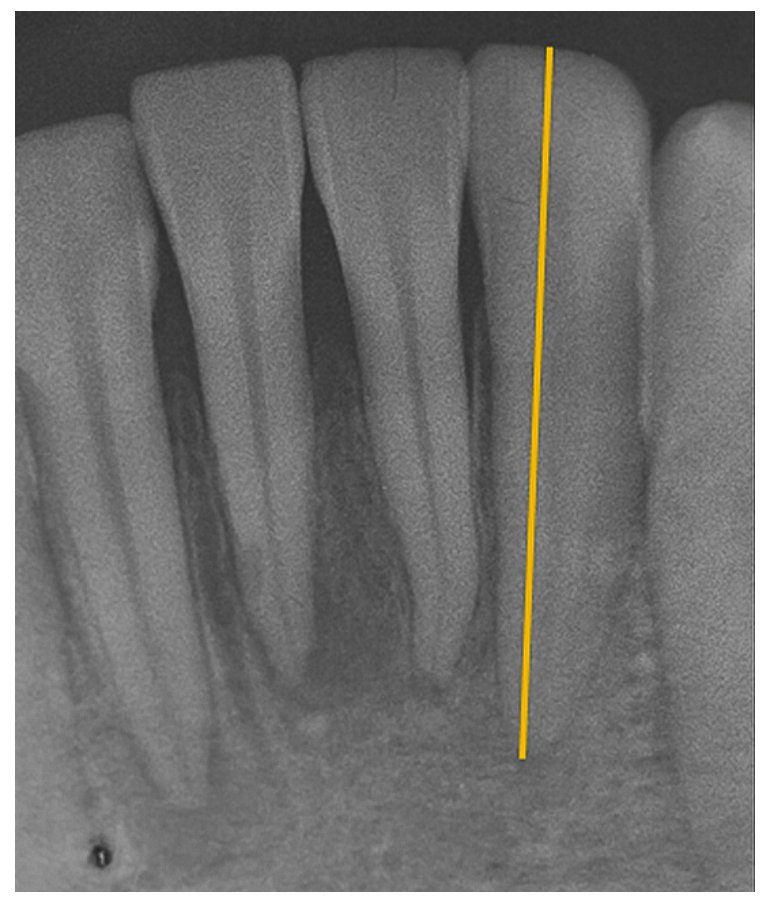

Figura I.9 - Imagem obtida por radiografia periapical, destaque para a técnica de mensuração da altura total do incisivo lateral inferior esquerdo.

O canino é o dente que, per si, pode ter maior relevância na interpretação médico-legal. Na dentição definitiva, os caninos estão localizados entre os incisivos laterais e os primeiros pré-molares enquanto na dentição decídua situam-se entre os incisivos laterais e os primeiros molares decíduos. Os caninos, nomeadamente os inferiores, são marcados por um dimorfismo sexual [8-14]. A determinação do género, por técnicas odontométricas, pode ser efetuada pelo cálculo do índice mandibular do canino (IMC = relação entre a mensuração mesio-distal coronária e a largura do arco mandibular). Um valor de IMC superior a 0,274 localiza o indivíduo no género masculino, com uma previsão de 84,5\%; um valor de IMC inferior a 0,274 (valor standard) localiza o indivíduo no género feminino, com uma previsão de $87,5 \%[9,15,16]$. Outros cálculos como o índice de robustez $(\mathrm{IR}=$ relação entre as mensurações mesio-distal e vestíbulo-lingual coronárias do canino) e o módulo da coroa ( $\mathrm{MC}=$ média aritmética entre as mensurações mesio-distal e vestíbulo- lingual coronárias do canino) permitem-nos encontrar valores significativamente superiores no género masculino [14].

Cada elemento dentário pode ser morfológico e anatomicamente decomposto em cinco faces (figs. I.10 e I.11), pelo que uma grande combinação de padrões dentários pode ser caracterizada num mesmo indivíduo, o que torna possível a identificação positiva.

\section{- Odontometrias de grupo}

Podemos considerar à semelhança do que ocorre com o poder discriminador de um marcador genético, que a combinação das características conjuntas de cada dente permitirá uma maior caracterização individual. Assim, na prática forense existem mensurações que podem englobar mais do que um dente, como por exemplo, a distância intercanina (fig. I.12).

A distância intercanina pode ser medida através dos vértices cuspídeos do canino (utilizado no IMC) [8-13] ou através do ponto de maior convexidade da face vestibular entre os caninos da mesma arcada (fig. I.7 e I.12). Esta mensuração encontra-se relacionada com a idade e o género do indivíduo, sendo maior nos indivíduos do género masculino $[16,17]$. 


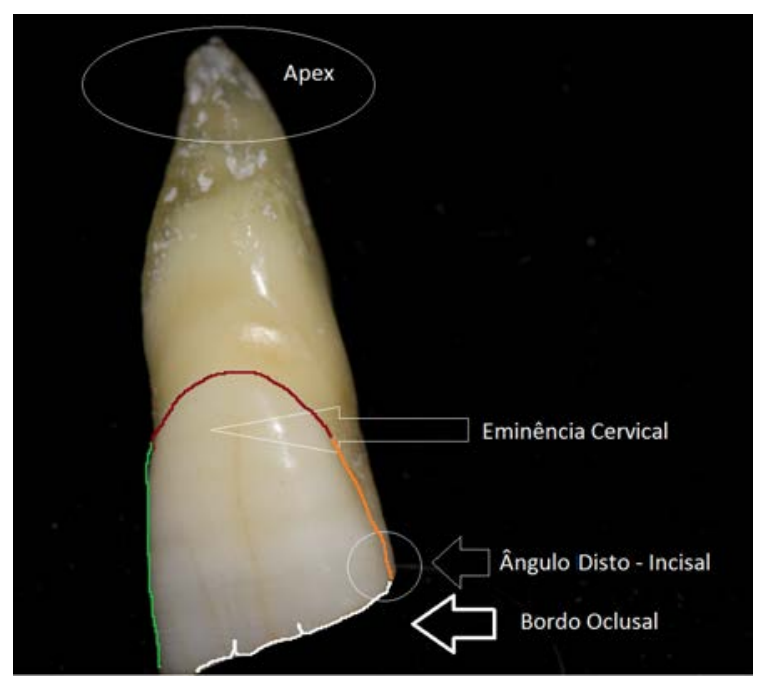

Figura I.10 - Fotografia do 11, destaque para os contornos coronários da sua face vestibular: contorno oclusal ou incisal (branco) marcando os três lobos (distal, central e mesial); contorno distal (laranja) com destaque para o ângulo disto-incisal; contorno cervical ou linha do colo vestibular (vermelho) e o contorno mesial (verde). Destaque para a estrutura anatómica coronária, eminência cervical.

Os seis dentes anteriores, incisivos e caninos, são referências no estudo das marcas de mordidas (fig. 1.7). O somatório das mensurações mesio-distais destes dentes é maior no homem do que na mulher [13].

A preocupação de qualquer técnica de análise de evidências é a reprodução dos resultados. As limitações fisiológicas e iatrogénicas das odontometrias associadas à variabilidade intra e interindividual no registo das mesmas, condicionam a interpretação dos resultados. Pelo exposto, a análise de odontometrias na identificação deve ser cautelosa e preferencialmente englobar a comparação de registos de um mesmo

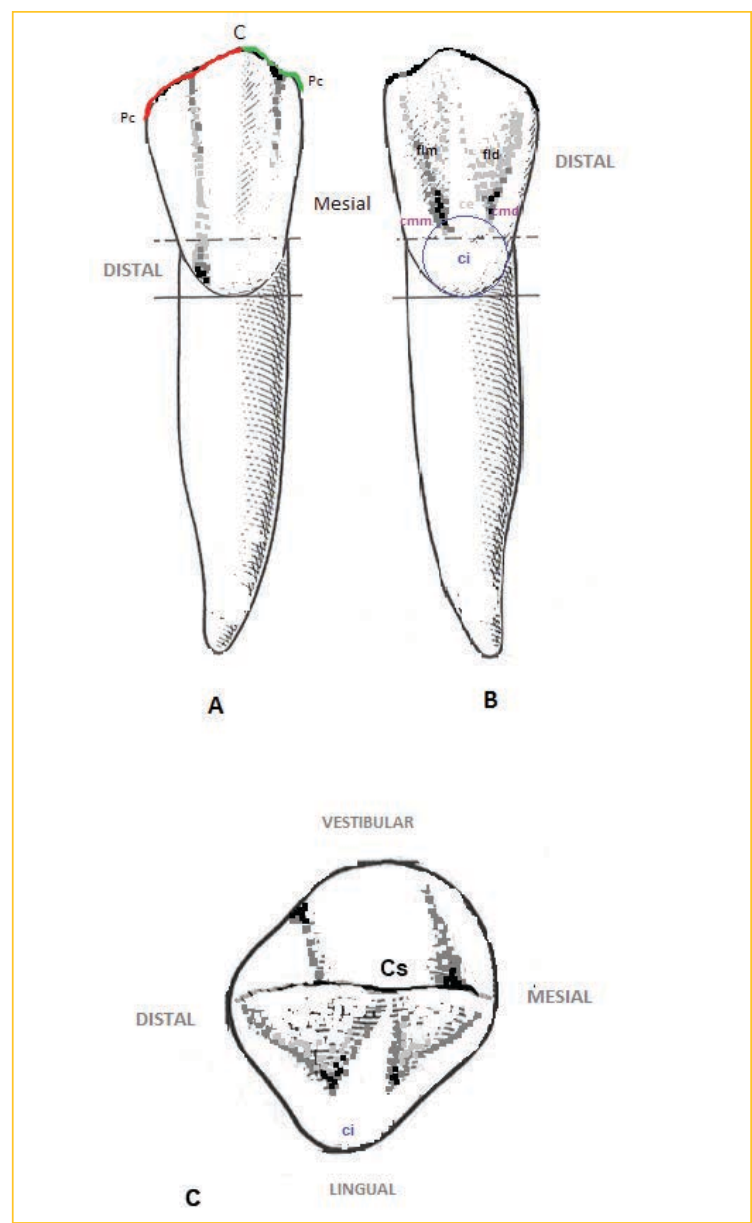

Figura I.11 - Apresentação esquemática e descrição sumária do canino inferior definitivo. Numa face vestibular (A) podemos caracterizar a coroa, com uma cúspide (Cs) desviada para mesial; duas arestas cuspídeas, mesial (a verde) e distal (a vermelho); e pontos de contato, mesial e distal, em relação com os dentes adjacentes. Numa face lingual (B) podemos caracterizar a coroa por apresentar um cingulum (ci) desviado para distal; duas cristas marginais, mesial (cmm) e distal (cmd); e duas fossas linguais, mesial (flm) e distal (fld), separadas por uma discreta crista de esmalte (ce). Em relação à porção radicular, numa face distal é visível um longo sulco longitudinal, demarcando duas porções, vestibular e lingual, separadas apenas no terço apical. A face oclusal (C) alongada no sentido vestíbulo-lingual apresenta uma separação em duas porções de grande convexidade, vestibular e lingual, pelo limite oclusal da cúspide. 


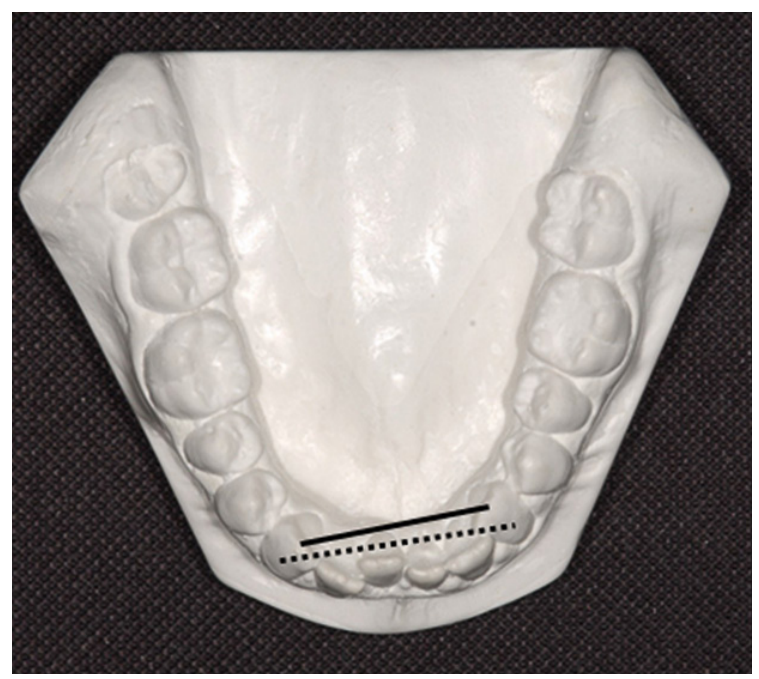

Figuras I.12 - Fotografia de modelo em gesso da arcada dentária inferior. O traço contínuo destaca a distância intercanina medida entre vértices cuspídeos, e o tracejado a maior distância intercanina medida no ponto mais vestibular da linha de maior contorno do dente.

indivíduo, incluindo exames complementares de avaliação.

\section{I.3.2. ODONTOGRAMA}

O preenchimento do odontograma compreende o registo das características de uma dentadura, ou seja, os dentes presentes num determinado momento, bem como as características das reabilitações de que possa ser portador.

Os dentes presentes podem corresponder a uma dentição decídua (representados por 51 a 55,61 a 65,71 a 75 e 81 a 85) ou definitiva (11 a 18; 21 a 28, 31 a 38 e 41 a 48). Segundo as orientações da Interpol [1], os dentes ausentes devem estar assinalados sob a forma de cruz no odontograma e neste devem igualmente ser registadas eventuais restaurações, reabilitações dentárias (fixas e removíveis, parciais ou totais, provisórias ou definitivas) ou tratamentos endodônticos ou pulpares presentes (fig. I.13). De acordo com estas mesmas orientações, as restaurações a amálgama devem estar assinaladas a sombreado/preto, enquanto a verde correspondem as restaurações a compósito e a vermellho a liga de ouro.

Em relação a cada dente podemos definir outros parâmetros para a sua caracterização, tais como o facto de serem inclusos ou semi-inclusos, estarem malposicionados ou em giroversão. Os dentes podem apresentar detalhes anatómicos, como por exemplo, tubérculos ou perda de tecido mineralizado por cárie, desgaste fisiológico (atrição), mecânico (abrasão) e químico (erosão). Os dentes podem estar relacionados com hábitos individuais (ex.piercing) ou ocupacionais (ex.talhe do cachimbo). No que concerne à porção radicular da estrutura dentária podem igualmente ser registadas algumas particularidades distintivas, designadamente áreas de reabsorção radicular, fraturas, calcificações da cavidade pulpar, anatomia radicular (quanto à forma e ao número) e hipercementose. Quanto ao osso alveolar este pode ser caracterizado pelo seu trabeculado, pela eventual presença de abcessos e formações quísticas, pela relação septo ósseo interproximal/coroa anatómica, pelo espaço periodontal ou pela presença ou não de cálculos. 

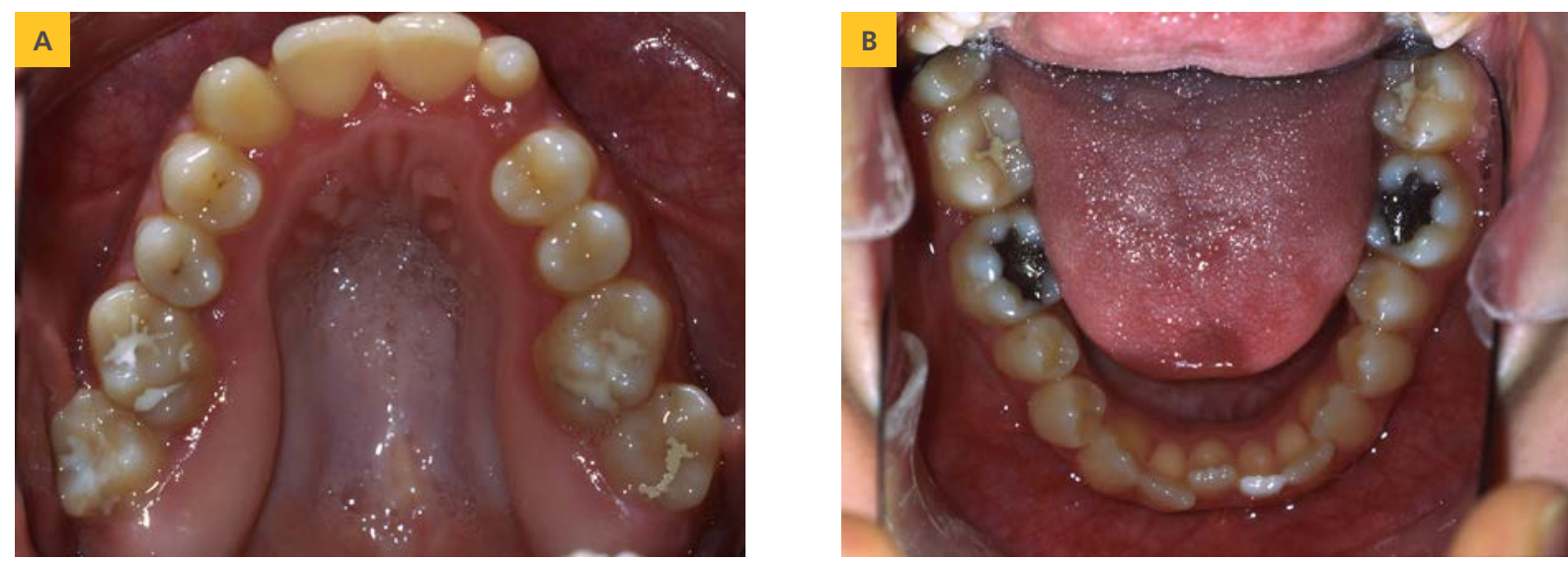

C

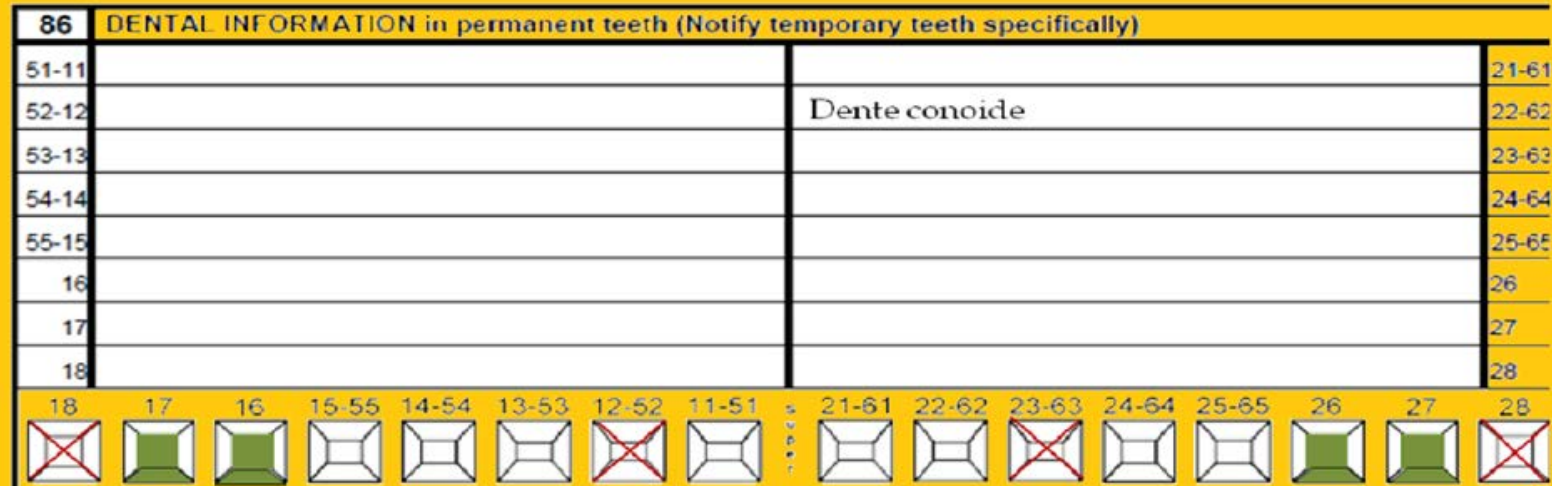

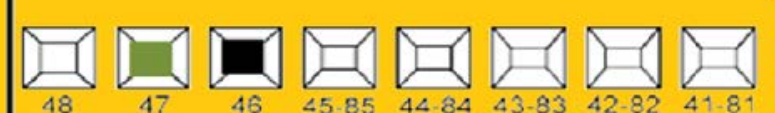

$\square$
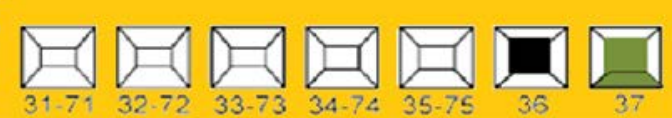

$\frac{X}{38}$
$\frac{38}{37}$
$\frac{36}{35-75}$
$\frac{34-74}{33-75}$
$\frac{32-72}{31-71}$

Figuras I.13 (A,B e C) - Preenchimento do odontograma. (A) Fotografia intraoral da arcada dentária superior. (B) Fotografia intraoral da arcada dentária inferior.(C) Correspondência das características da dentadura, numa esquematização uniformizada, o odontograma. A face oclusal é representada pelo retângulo central, para cada dente; lateralmente ao qual se dispõe as porções vestibular, palatino/lingual, mesial e distal. São utilizadas distintas cores na sinalização das reabilitações. Em verde estão representadas as restaurações a compósito, a côr preta corresponde às restaurações a amálgama, enquanto a cruz assinala os dentes ausentes com características de perda ante mortem. 


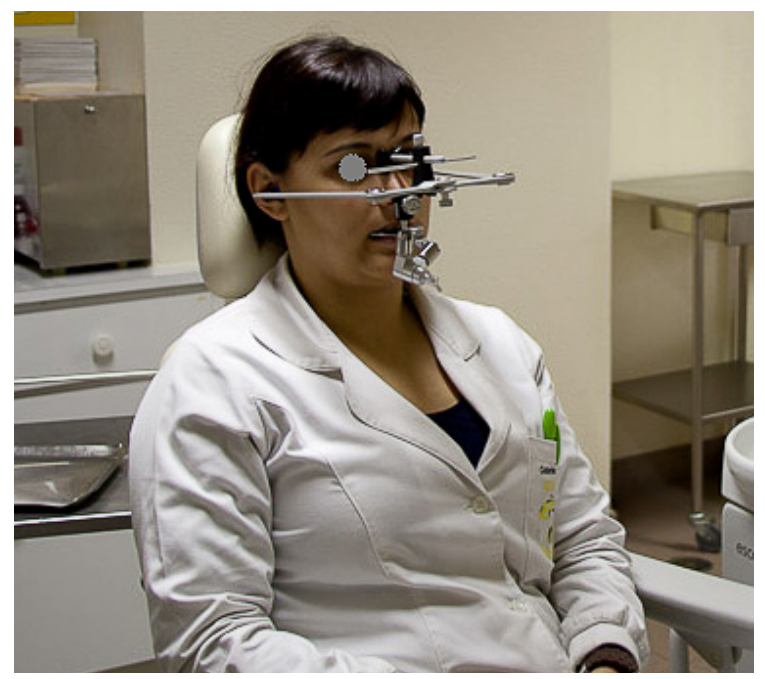

Figura I.14 - Fotografia de calibração da posição de relação cêntrica com arco facial de articulador SAM2PXTM.

\section{I.4. ANÁLISE OCLUSAL}

Uma parte integrante do método dentário no processo de identificação e na avaliação do dano corporal é o estudo da relação interdentária no sistema estomatognático.

A mandíbula é o único osso móvel dos ossos do crânio e define a articulação temporomandibular, também designada por articulação escamoso-mandibular ou crânio-mandibular.

As componentes dentária e muscular definem as posições e os movimentos da relação mandíbula/maxilar, sendo que estes podem ser estudados num articulador. Neste equipamento

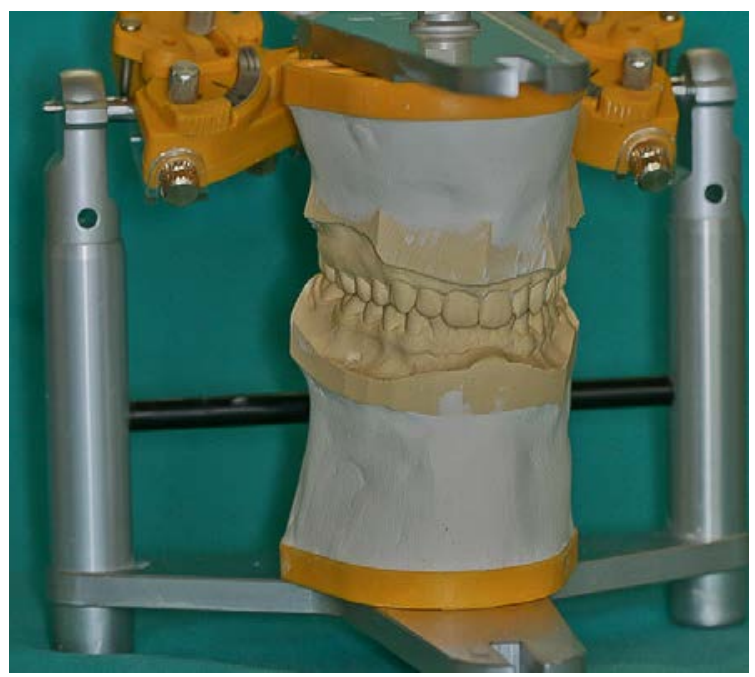

Figura I.15 - Montagem em articulador ou simulador de movimento entre as duas arcadas dentárias tipo SAM2PX ${ }^{\mathrm{TM}}$

são registadas as características de diversos parâmetros, entre as quais, a posição estática de referência e o respetivo registo dentário, de modo a reproduzir as posições e os movimentos dentários de determinado indivíduo.

Relembre-se que a posição de relação cêntrica (RC) pode ser considerada como a posição mais recuada do côndilo mandibular (figs. I.14 e I.15), frequentemente coincidente com a posição em que se obtém o maior número de contactos entre os dentes oponentes, designada por posição de intercuspidação máxima hábitual (PIM) (fig. I.16). Esta posição pela sua fácil determinação é usualmente aplicada no âmbito da Medicina 


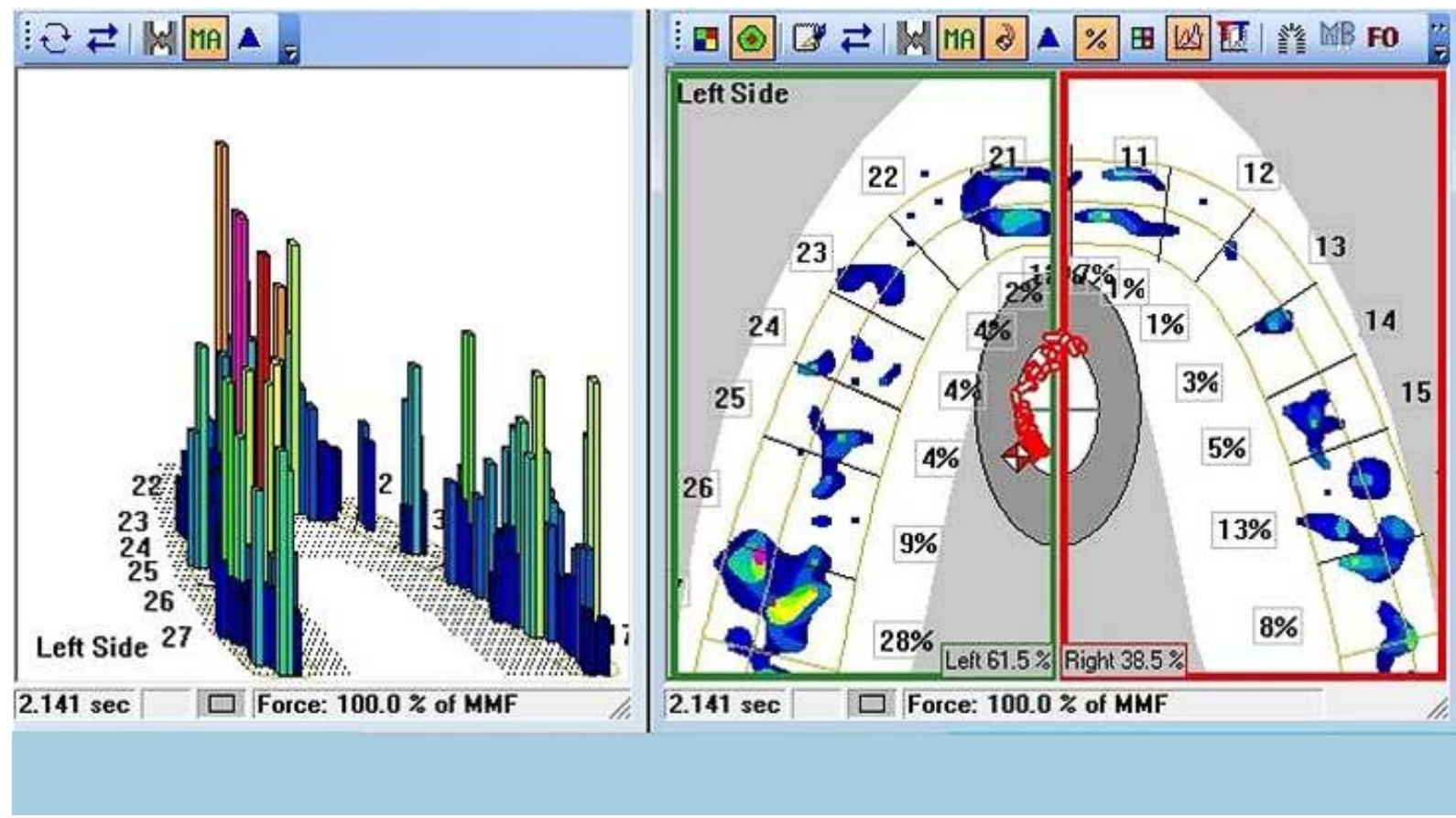

Figura I.16 - Registo de T-Scan ${ }^{\circledR}$ III HD em posição de PIM. Este equipamento permite registar o local e ponto de contacto entre os dentes oponentes em PIM. O perfil da esquerda corresponde a uma visualização 3D da intensidade das forças na posição de fecho das duas arcadas dentárias, correspondendo as colunas a vermelho à maior intensidade de carga; o perfil da direita corresponde à visualização 2D das áreas de contacto dos dentes inferiores nos dentes superiores, na mesma posição interarcadas.

Dentária Forense. O registo entre os dentes de ambas as arcadas oponentes é um estudo individualizante [18].

Podemos considerar os movimentos da mandíbula, orientados pelo grupo de dentes anteriores, considerando-se a guia incisiva (executada pelos incisivos) em relação com o movimento de protrusão, ou seja, de avanço mandibular, e a guia canina em relação com os movimentos de lateralidade (fig. I.17). No movimento de protrusão os côndilos deslizam sobre a eminência articular e os incisivos inferiores sobre a face palatina dos superiores, com a desoclusão dos dentes posteriores, originando o deslizamento das encostas (detalhe anatómico da cúspide) mesiais dos dentes inferiores pelas encostas distais dos dentes superiores.

No movimento de lateralidade da mandíbula existe uma função idêntica para um determinado grupo de dentes, sob a orientação de uma guia canina, com a desoclusão dos dentes posteriores para o lado contrário ao movimento ou lado não trabalhante.

No que se refere à oclusão devem ser pesquisadas as áreas de contacto dos dentes oponentes localizados nas respetivas arcadas, quando em posição estática de referência, bem como as guias canina e incisiva e as interferências dentárias 

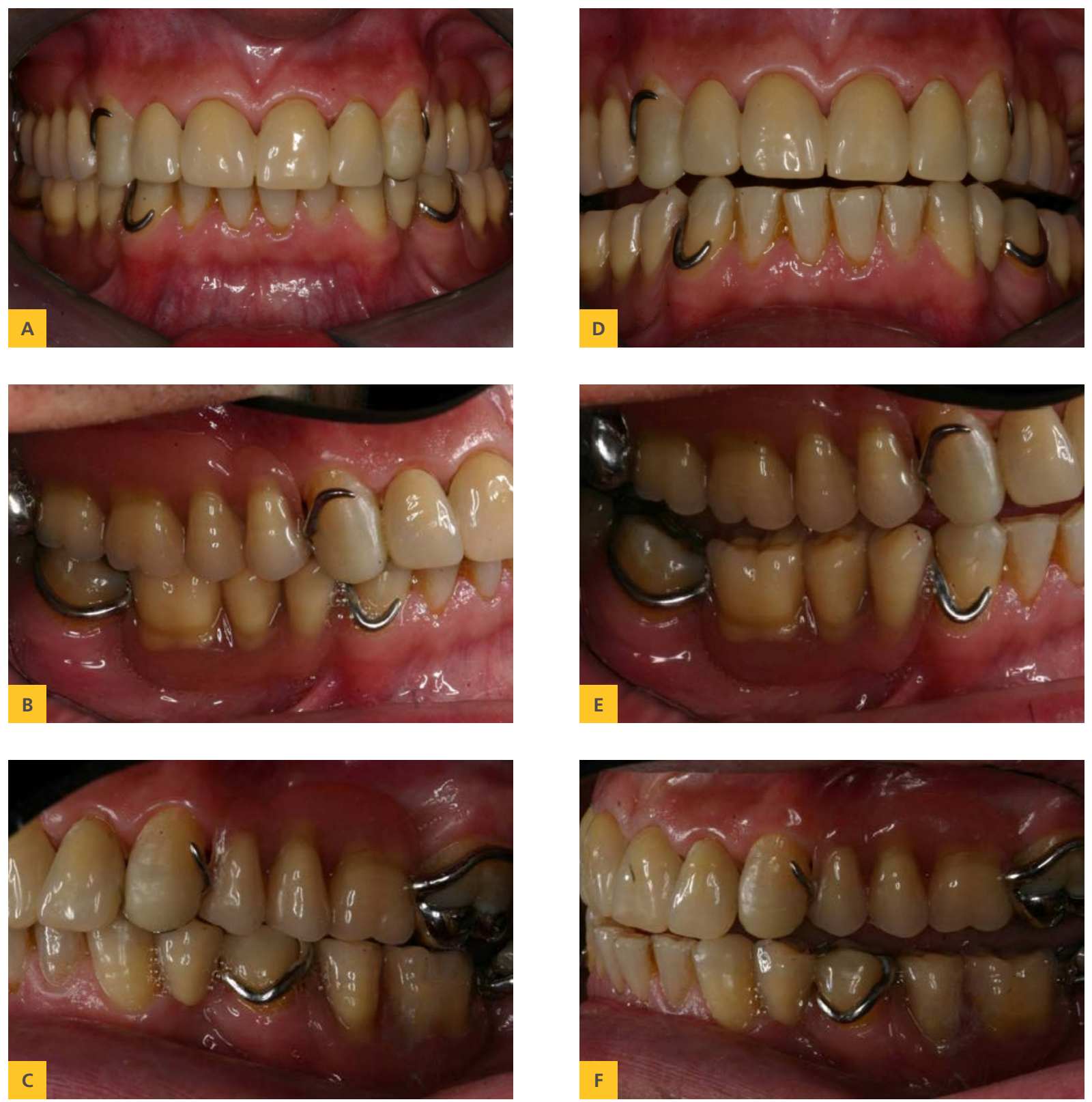

Figura I.17 (A,B,C,D,E e F) - Registos fotográficos de distintas posições inter-arcadas. (A) Registo frontal da posição em PIM. (B) Registo lateral esquerdo da posição em PIM. (C) Registo lateral direito da posição em PIM. (D) Guia canina em movimento de protrusão. (E) Vista lateral esquerda com movimento de lateralidade para a direita, exibindo o contacto dos caninos e prémolares. (F) Vista lateral direita com movimento de lateralidade para a direita, evidenciando desoclusão dos dentes posteriores. Em todas as imagens observa-se a presença de uma reabilitação superior (17, 16, 15, 14, 24, 25 e 26) e inferior (37, 36, 35, 44, 45 e 46) por prótese removível esquelética, bem como um revestimento oclusal no dente 27 (segundo molar superior esquerdo), de modo a nivelar o plano oclusal, ou seja, a curva de Spee. Cortesia Júlio Fonseca e Pedro Nicolau. 
(contactos que dificultam os movimentos mandibulares), se existentes. No seu conjunto, estas características podem ser consideradas individualizantes [18].

Atualmente a procura de uma melhoria estética facial, de uma correção funcional dentária ou da eliminação de uma oclusão passível de desencadear uma patologia dentária fundamentam a elevada frequência de reabilitações que recorrem à Medicina Dentária. Não podemos deixar de destacar que as reabilitações ortodônticas e protéticas contribuem para a estandardização destes dados, dificultando a sua individualização. Sendo que a patologia faz a diferença, destacamos que as caracteristicas mais individualizantes encontram-se frequentemente associadas a situações disfuncionais.

A categorização da patologia dentária e/ou esquelética coloca o doente com características definidas, num dos seguintes grupos: défice ou excesso ântero-posterior da mandíbula, défice ou excesso ântero-posterior do maxilar, défice ou excesso vertical do maxilar, rotação do complexo maxilo-mandibular, mordidas abertas (dentes sem contacto na posição estática de referência) ou profundas (acentuado trespasse vertical, ou seja, interposição dos dentes inferiores na arcada dentária superior) e assimetrias faciais.

Um avanço mandibular tem associadas alterações faciais, sendo que, numa vista de perfil, observa-se o aumento da proeminência do mento, a diminuição do vermillion do lábio inferior, o aumento da proeminência do lábio inferior e a diminuição da convexidade de perfil, enquanto numa vista frontal, verifica-se o aumento do andar inferior da face e a posição revirada do lábio inferior. Por outro lado, um recuo mandibular em vista de perfil, geralmente está associado a uma diminuição da proeminência ântero-posterior da mandíbula e a uma redução da exposição do vermillion do lábio inferior. Esta condição em vista frontal, reflete-se numa diminuição da proeminência mandibular, um vermillion do lábio superior mais proeminente e uma diminuição do andar inferior da face [4].

No que concerne ao avanço maxilar, numa vista de perfil, reflete o aumento da proeminência paranasal, a elevação da ponta do nariz, o aumento da proeminência do lábio superior e a diminuição da proeminência relativa do mento e do nariz. Numa vista frontal, esta condição apresenta-se com um aumento da largura da base do nariz, um aumento da proeminência e exposição do vermillion do lábio superior, tornando a zona paranasal mais proeminente [4].

A manutenção de restos radiculares e implantes endoósseos para suporte de uma reabilitação coronária protética, bem como uma correção oclusal, dificultam a aplicação de métodos antropológicos em estudos prospetivos na população atual [8]. 


\section{I.5.REFERÊNCIAS}

[1] Disasters Victim identification Guide Interpol. (2009). Disponível em: http://www.interpol.int.

[2] Testut, L., Latabjet, A. (1986). Tratado de Anatomia Humana. Tomo I. Barcelona: Edições, Salvat SA.

[3] Lautrou, A. (2006). Anatomie Dentaire. Paris: Edições El Sevier Masson.

[4] Arnett, G.W., McLaughlin, R.P. (2004). Facial and Dental Planning for Orthodontists and Oral Surgeons. Edições Mosby, Elsevier Limited.

[5] Okeson, J.P. (2008). Management of temporomandibular disorders and occlusion. (6 ${ }^{\circ} \mathrm{ed}$.). St. Louis: CV Mosby.

[6] Houston, W.J.B., Stephens, C.D., Tulley, W.J. (1992). A Textbook of Orthodontics. (1 ${ }^{\circ} \mathrm{ed}$.). Great Britain: Editores Wright.

[7] Acharya, A.B., Prabhu, S., Muddapur, M.V. (2011). Odontometric sex assessment from logistic regression analysis. Int J Legal Med, 125(2), pp.199-204.

[8] Rao, N.G., Rao, N.N., Pai, M.L. e col. (1989). Mandibular canine index: a clue for establishing sex identity. Forensic Sci Int, 42, pp.249-54.

[9] Duraiswamy, P., Tibdewal, H., Patel, K. e col. (2009). Sex determination using mandibular canine index in optimal-fluoride and high-fluoride areas. J Forensic Dent Sci, 1(2), pp.99-103.

[10] Reddy, V.M., Saxena, S., Bansal, P. (2008). Mandibular Canine index as a sex determinant: A study on the population of western Uttar Pradesh. J. Oral Maxillofac Pathol, 12(2). pp.56-9.

[11] Acharya, A.B., Mainali, S. (2009). Limitations of the mandibular canine index in sex assessment. J Forensic Leg Med, 16(2), pp.67-9.

[12] Achary, A.B., Angadi, P.V., Prabhu, S. e col. (2011). Validity of the mandibular canine index $(\mathrm{MCl})$ in sex prediction: Reassessment in an Indian sample. Forensic Sci Int, 204(13), pp.e1-4.

[13] Kaushal, S., Patnaik, V.V.G., Agnihotri, G. (2003). Mandibular Canines In Sex Determination. J Anat Soc Indian, 52(2), pp.119-24.

[14] Pereira, C. (2005). Contribuição para a Identificação Humana a partir dos dentes - Determinação do Dimorfismo Sexual em População adulta portuguesa. (Dissertação de Tese de Mestrado em Medicina Legal publicada). Universidade de Lisboa, Faculdade de Medicina

[15] Rao, N.G., Rao, N.N., Pai, M.L. e col. (1989). Mandibular Canine Index - A Clue For Establishing Sex Identity. Forensic Sci. Int, 42, pp.249-254.

[16] Srivastava, C.P. (2010). Correlation of Odontometric Measures in Sex Determination. J Indian Acad Forensic Med, 32(1), pp.56-61.

[17] Krogman, W.N., Iscan, M.Y. (1987). The human skeleton in Forensic Medicine. ( $2^{\mathrm{a} e d}$ ). Springfield: Charles, C Thomas Publisher.

[18] Corte-Real, A.T., Filter, V.P., Silveira, A., Fonseca, J., Alves S., Rodrigues, M.J. (2013). The T-Scan $®$ System a tool for forensic science. J For Odonto-Stomol, 31 supl.1, pp.51-52. 